\title{
PHYSIOLOGICAL SIGNALS AND VEHICLE PARAMETERS MONITORING SYSTEM FOR EMERGENCY PATIENT TRANSPORTATION
}

\author{
Dhiraj Sunehra $^{1}$, Thirupathi Samudrala ${ }^{2}$, K. Satyanarayana ${ }^{3}$, M. Malini ${ }^{4}$ \\ ${ }^{1}$ JNTUH College of Engineering, Jagtial, Karimnagar - 505 501, A.P., India \\ ${ }^{2}$ JNTUH College of Engineering, Jagtial, Karimnagar - 505 501, A.P., India \\ ${ }^{3}$ University College of Engineering, Osmania University, Hyderabad - 500 007, A.P., India \\ ${ }^{4}$ University College of Engineering, Osmania University, Hyderabad - 500 007, A.P., India
}

\begin{abstract}
The developments in semiconductor electronics and wireless communication have enabled development of new systems for monitoring patient's health parameters in emergency and alerting the doctors by sending the monitored data from patient's location. It takes certain amount of time, to begin the treatment of the patient after reaching the hospital, in view of conducting various diagnostic tests to know patient's health status. This time is crucial in the golden hour. If patient's physiological parameters record is sent from emergency vehicle to the monitoring station using wireless technology, while transporting the patient to the hospital, this data would help in prior diagnosis of patient's health condition and making necessary arrangements for initiating the treatment. In this paper, we have reported a prototype of emergency patient monitoring system that monitors vital physiological parameters and vehicle parameters such as pulse rate, oxygen saturation level, body temperature, location and speed of vehicle and fuel level.
\end{abstract}

Keywords: Pulse rate, Oxygen saturation, Body temperature, GPS, GSM, Microcontroller

\section{INTRODUCTION}

In India, the Emergency Management and Research Institute (EMRI) is handling three types of $24 \times 7$ emergency services, viz. medical, police and fire through the 108 emergency services at free of cost. These services are provided in about 14 states and 2 union territories of India with 5460 ambulances (http://www.emri.in/index.html). Remote physiological parameter monitoring allows continuous transmission of emergency patient information to the doctor or healthcare providers. This information is also useful to guide the emergency vehicle to a particular hospital based on the patient's monitored data. This type of system enables in saving the emergency patient by pre-alerting the particular healthcare providers. The proposed system redefines the emergency maintenance system by monitoring the physiological parameters and vehicles parameters. Especially this type of emergency management system is required for rural areas. The work presented in this paper focuses on measurement and integration of physiological and vehicle parameters using LPC 2148 microcontroller, GPS and GSM. This type of system is required for continuous monitoring of patient's physiological parameters and forecasting the vehicle condition.

\section{DESCRIPTION OF EMERGENCY PATIENT}

\section{AND VEHICLE MONITORING SYSTEM}

Figure 1 shows the block diagram of the developed system for continuous monitoring of various physiological parameters. Pulse rate is measured from the photo plethysmography (PPG) signal, oxygen saturation $\left(\mathrm{SpO}_{2}\right)$ is measured by computing the $\mathrm{AC}$ and $\mathrm{DC}$ components of both the red and infrared LEDs corresponding PPG signals, and body temperature is measured using LM35 temperature sensor. The vehicle parameters such as fuel level is calculated using resistive network, and vehicle location and speed are computed by Global Positioning System (GPS). The measured data is interfaced to the LPC2148 microcontroller. LPC2148 is an ARM7TDMI-S based highperformance 32-bit RISC microcontroller with $512 \mathrm{~KB}$ onchip Flash ROM, 32KB RAM, Vectored Interrupt Controller, two 10-bit ADCs with 14 channels, two UARTs, two 32-bit timers and general purpose I/O pins. After processing data in the microcontroller, the parameters are displayed on LCD display and transmitted to a central monitoring station using Global System for Mobile communication (GSM) technology every two minutes duration. The system consists of consists of pulse rate detector board, temperature sensor and pulse oximeter board to acquire the physiological signals, a fuel level sensor for indicating the fuel level in the vehicle and GPS is used to provide location and speed of the vehicle. 


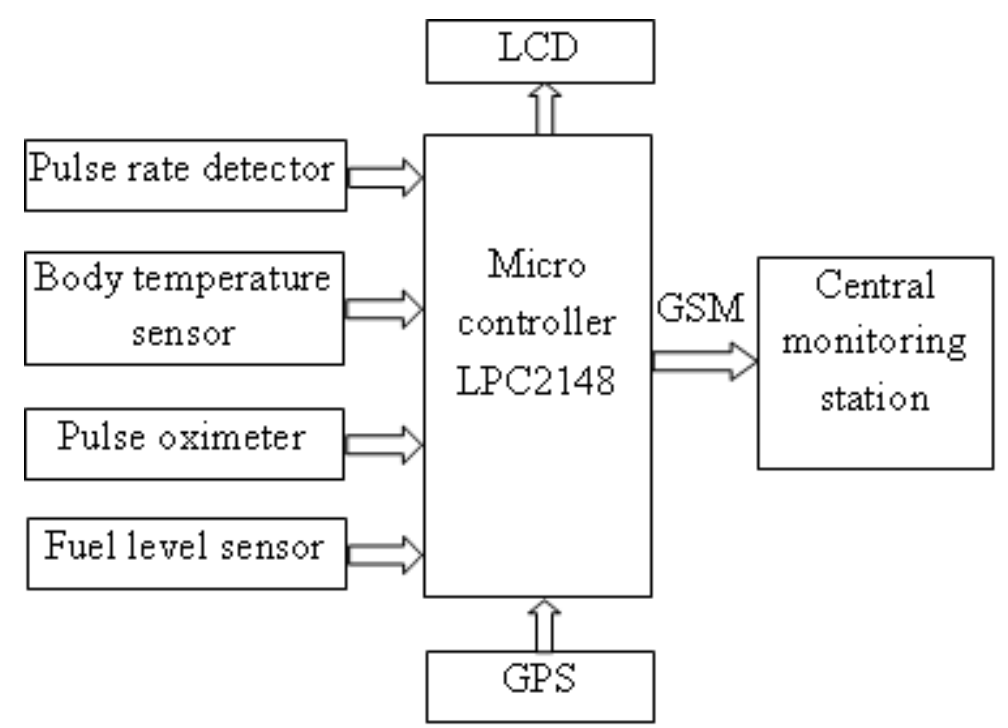

Fig. 1. Block diagram of the Emergency Patient and Vehicle Monitoring System

The ambulance unit comprises of physiological signals acquisition modules, LCD display, GSM and GPS. The core unit of the signal acquisition module is a microcontroller (LPC2148). The microcontroller obtains the amplified and conditioned signals, and then it performs the interface with the GSM module using the supported standard AT commands.

\subsection{Pulse Rate Detector}

The schematic circuit of a pulse rate detector is shown in Fig. 2. It consists of a pulse detection circuit using TCRT5000 reflective sensor which includes an IR LED and a phototransistor. The IR LED transmits infrared light into the finger tip placed over the sensor unit, and the IR phototransistor receiver senses the light reflected back. The pulse rate sensor works on the principle of light modulation by blood flow at each pulse (http://www.sunrom.com). A two stage signal filter and amplifier circuit using LM358 opamp converts weak signal coming from the sensor into a pulse. The low pass filters have a cutoff frequency of about $2.34 \mathrm{~Hz}$. The maximum measurable pulse rate is therefore about 140 beats per minute (bpm). The output of filter circuit is of the order of $\mathrm{mV}$, and hence amplified for counting pulse rate by the microcontroller.

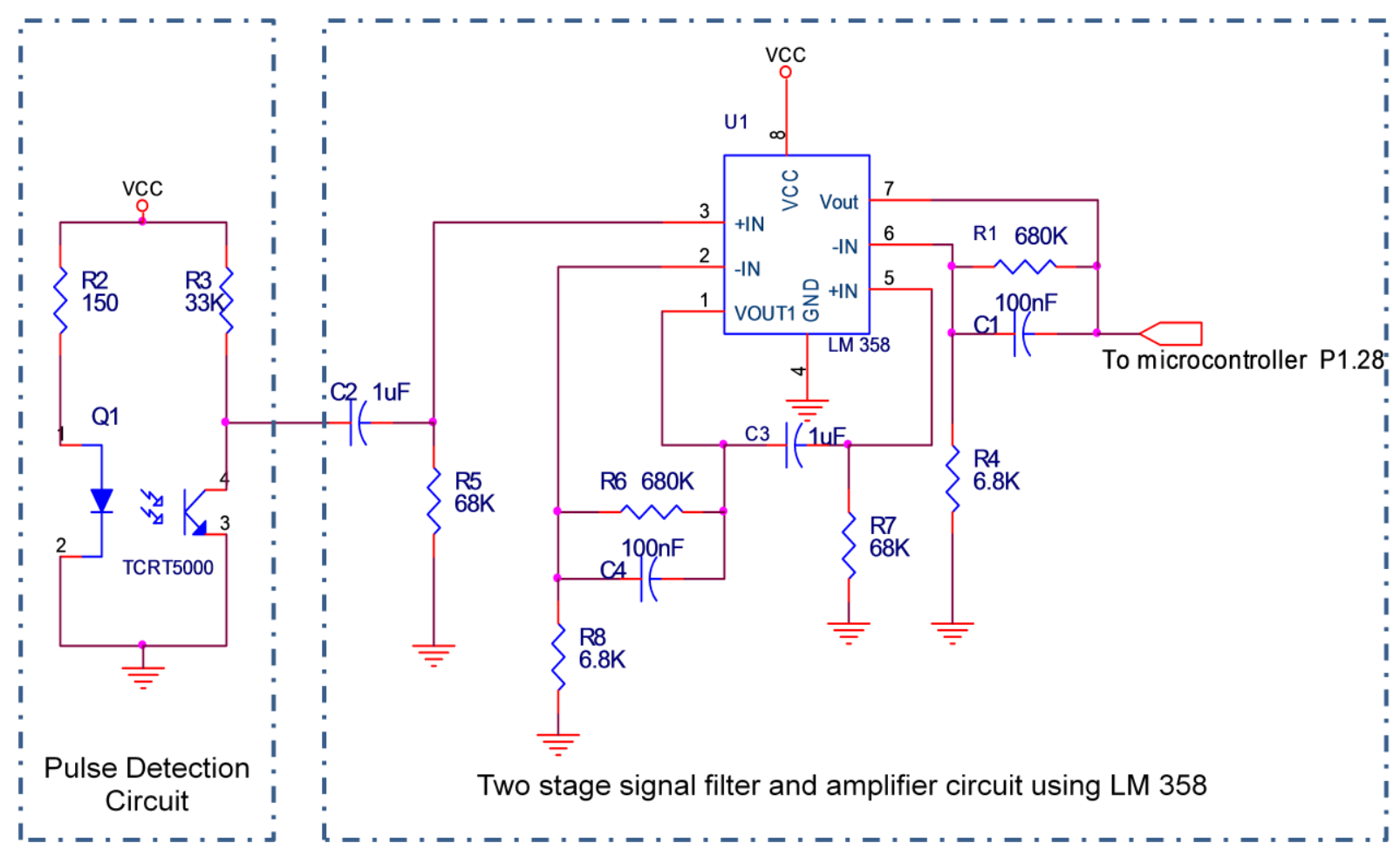


Fig 2 Schematic diagram of Pulse rate detector

\subsection{Temperature Sensor}

We have used a low-cost temperature sensor LM35 for measurement of body temperature. LM35 is a precision integrated-circuit temperature sensor, with an output voltage linearly proportional to the centigrade temperature (Scale Factor: $+10 \mathrm{mV} /{ }^{\circ} \mathrm{C}$ ). The sensor output voltage is fed to the ADC pins of microcontroller LPC 2148. The ADC gives digital output corresponding to the input analog voltage applied to it. The ADC output is calibrated to provide appropriate body temperature values. The LM35 does not require any external calibration or trimming to provide typical accuracies of $\pm 1 / 4^{\circ} \mathrm{C}$ at room temperature. It can operate from 4 to 30 volts. As it draws only $60 \mu \mathrm{A}$ from its supply, it has very low self-heating, less than $0.1^{\circ} \mathrm{C}$ in still air. The LM35 is rated to operate over a $-55^{\circ}$ to $+150^{\circ} \mathrm{C}$ temperature

(http://www.ti.com/lit/ds/symlink/lm35.pdf).

\subsection{Pulse Oximeter}

In pulse oximeter, the PPG detector consists of IR LED (910nm wavelength), red LED (660nm wavelength) and a photo detector. The IR and red LED blink in successive fashion by using a timing circuit (555 timer, $\mathrm{T}_{\text {on }}=$ $0.7\left(R_{1}+R_{2}\right) C_{2}$ and $\left.T_{\text {off }}=0.7 R_{2} C_{1}\right)$ and illuminates the skin (John Allen, 2007). The photo detector detects the transmitted light of both LEDs and generates the currents corresponding to the intensity of the light (Fig.3). The generated currents are converted into voltages by using a opamp based current to voltage converter. The voltage signal is fed to two sample and hold circuits to separate the IR and red LED related voltage signals. The sample and hold circuits consist of FET switches driven by the same timer, which is used to drive the IR and red LED driver circuit. The sampled signals are filtered using two band pass filters with cutoff frequency $0.1 \mathrm{~Hz}$ and $15 \mathrm{~Hz}$ to eliminate high frequency noise and the D.C. offset.

Then, it is amplified using LM741 opamp and sent through the ADC of the microcontroller. The microcontroller is programmed to calculate the ratio of red and IR LED signals, given by Eq.(1),

$$
R=\frac{A C_{R E D} / D C_{R E D}}{A C_{I R} / D C_{I R}}
$$

These are depicted in Fig.4. Once ' $R$ ' value is calculated from the two photo plethysmography (PPG) signals, $\mathrm{SpO}_{2}$ values are determined from ' $R$ ' by using Eq. (2),

$$
\% \mathrm{SpO}_{2}=K * \mathrm{R}
$$

' $\mathrm{K}$ ' is the proportionality constant which can be considered by calibration results (Bagha and Shaw, 2011). The complete schematic circuit of the pulse oximeter is shown in Fig. 5.

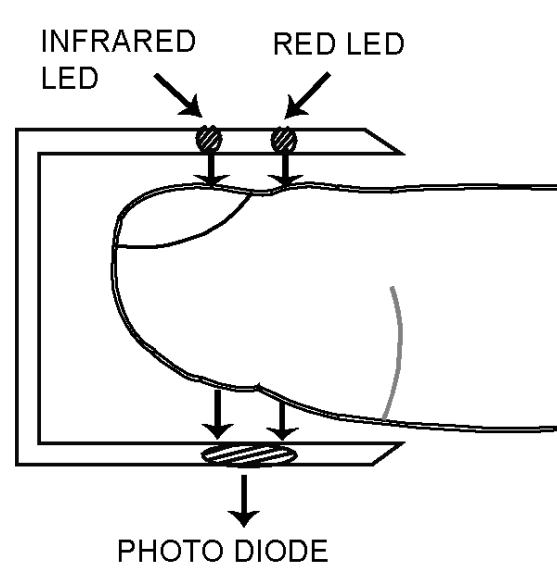

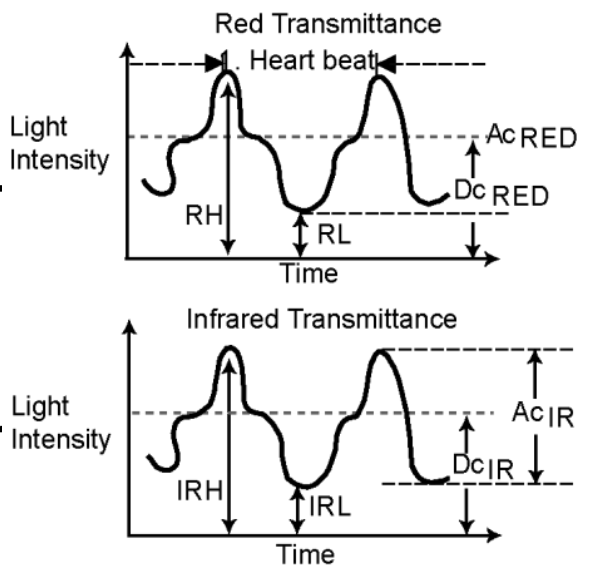

Fig. 4 Pulse oximetry waveforms 


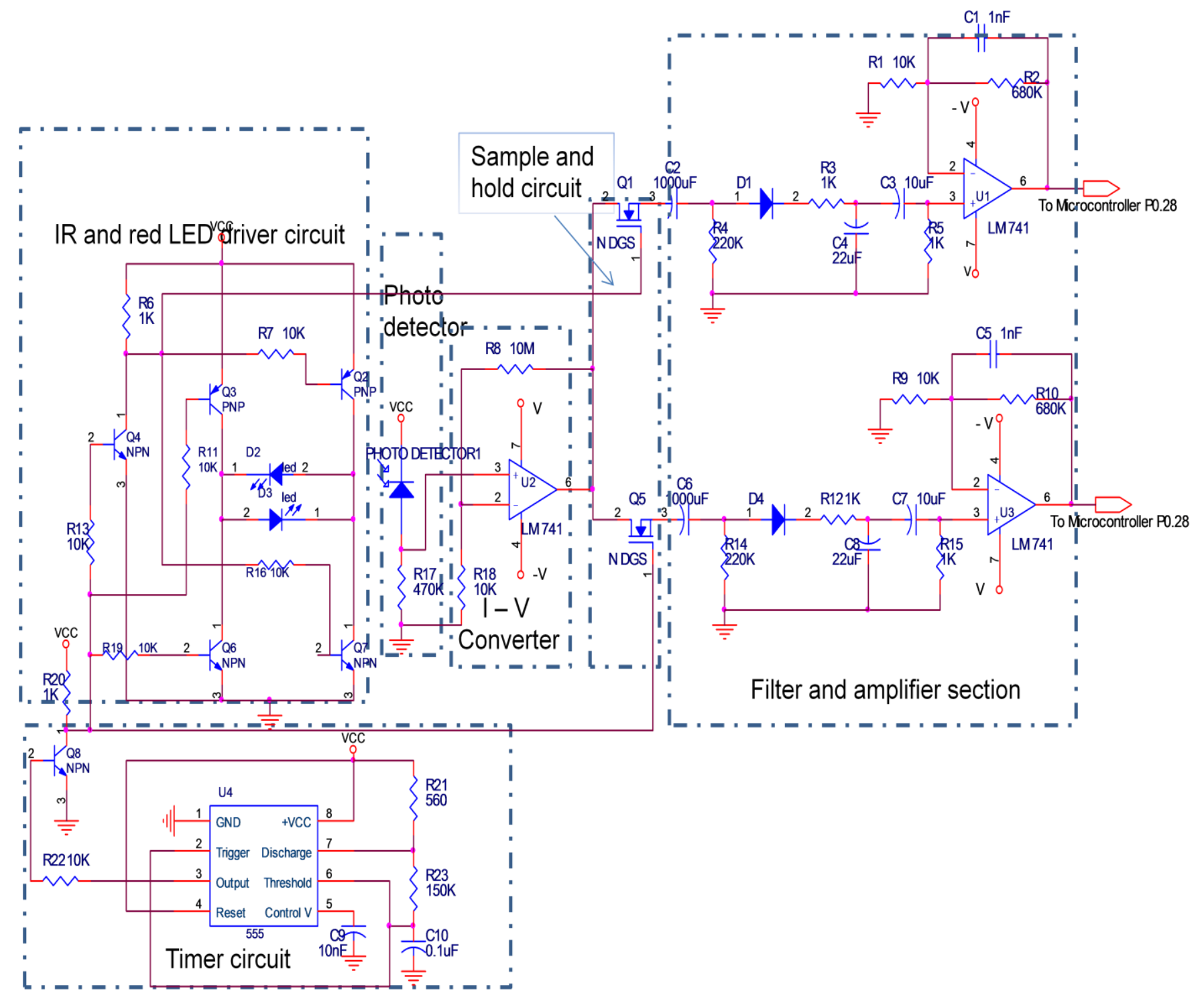

Fig. 5 Schematic circuit of Pulse oximeter

\section{RESULTS AND DISCUSSION}

Figure 6 shows the complete experimental setup of various modules interfaced to the LPC2148 microcontroller board. The program for measurement of pulse rate, oxygen saturation, body temperature, location and speed, fuel level is written in Embedded C, tested using Keil software and dumped into the microcontroller using Flash magic software. The software is programmed to provide the physiological and vehicle parameters every 2 minutes, which are transmitted to the base station mobile using GSM. The location and speed of the vehicle are measured using GPS. Fuel level indication is given whenever its level goes low. These parameters are also displayed on the LCD display which is supposed to be in the emergency vehicle. The measured physiological and vehicle parameters obtained at 2 minute interval are tabulated and shown in Table 1. 


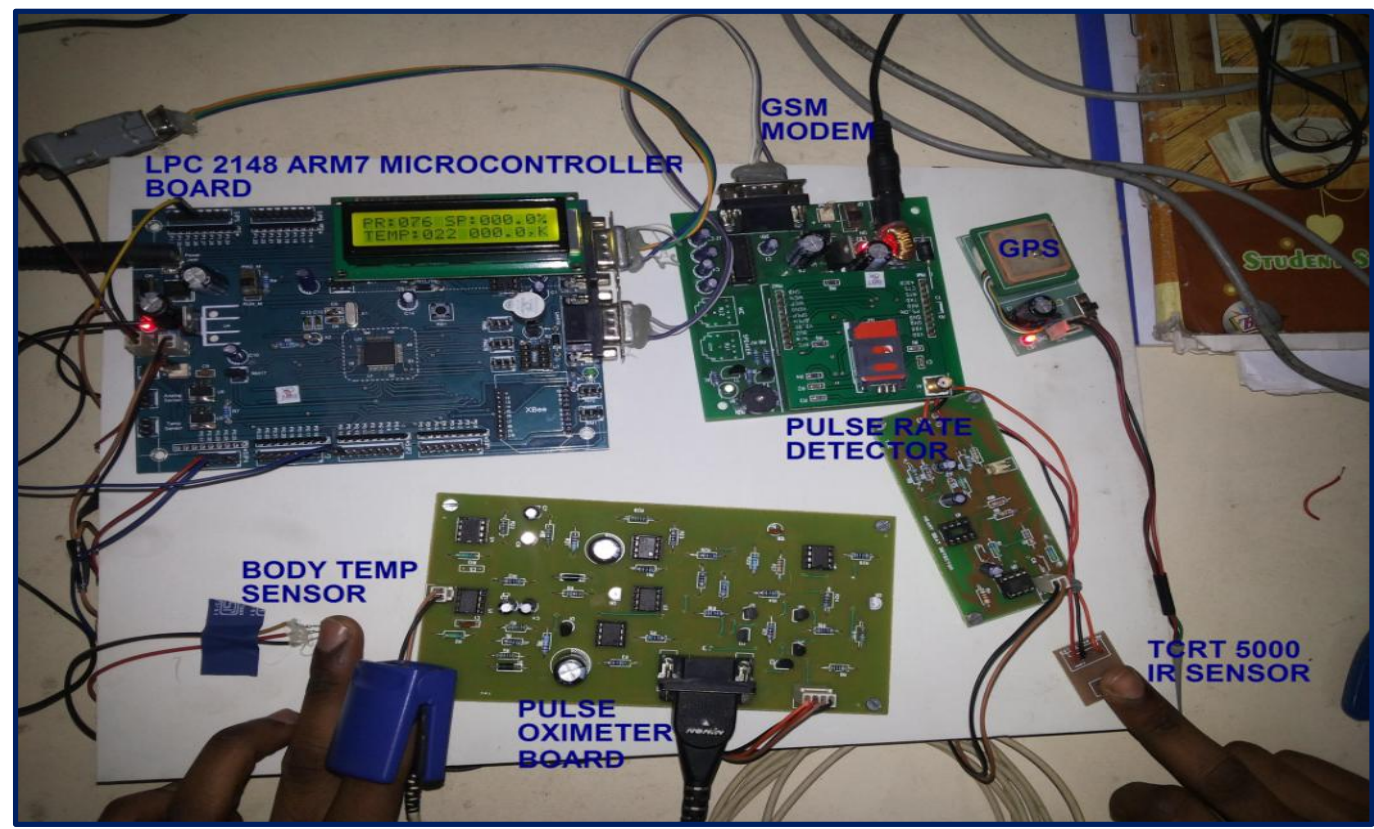

Fig. 6 Experimental setup of Physiological and Vehicle parameter monitoring system

Table 1 Measured Physiological and Vehicle parameters obtained at 2 minute interval for a stationary subject

\begin{tabular}{|l|l|l|l|l|l|l|}
\hline S.No. & $\begin{array}{l}\text { Pulse rate } \\
(\mathrm{bpm})\end{array}$ & $\begin{array}{l}\mathrm{SpO}_{2} \\
(\%)\end{array}$ & $\begin{array}{l}\text { Body temperature } \\
\left({ }^{\circ} \mathrm{C}\right)\end{array}$ & $\begin{array}{l}\text { Velocity } \\
(\mathrm{Km} / \mathrm{hr})\end{array}$ & $\begin{array}{l}\text { Fuel } \\
\text { Level }\end{array}$ & Location \\
\hline 1. & 80 & 96.9 & 38 & 0.00 & Low & $\begin{array}{l}17^{0} 25.1085^{\prime} \mathrm{N} \\
78^{0} 32.5713^{\prime} \mathrm{E}\end{array}$ \\
\hline 2. & 80 & 99.0 & 38 & 0.00 & Low & $\begin{array}{l}17^{0} 25.1085^{\prime} \mathrm{N} \\
78^{0} 32.5713^{\prime} \mathrm{E}\end{array}$ \\
\hline 3. & 76 & 97.3 & 37 & 0.00 & Low & $\begin{array}{l}17^{0} 25.1085^{\prime} \mathrm{N} \\
78^{0} 32.5713^{\prime} \mathrm{E}\end{array}$ \\
\hline 4. & 72 & 94.4 & 37 & 0.00 & Low & $\begin{array}{l}17^{0} 25.1085^{\prime} \mathrm{N} \\
78^{0} 32.5713^{\prime} \mathrm{E}\end{array}$ \\
\hline 5. & 76 & 96.5 & 37 & 0.00 & Low & $\begin{array}{l}17^{0} 25.1085^{\prime} \mathrm{N} \\
78^{0} 32.5713^{\prime} \mathrm{E}\end{array}$ \\
\hline
\end{tabular}

Figure 7 shows the sample message received by the base station mobile which is used to alert the doctor. A link of the google map location of the emergency vehicle is also included, in addition to the latitude and longitude information (Fig. 8).

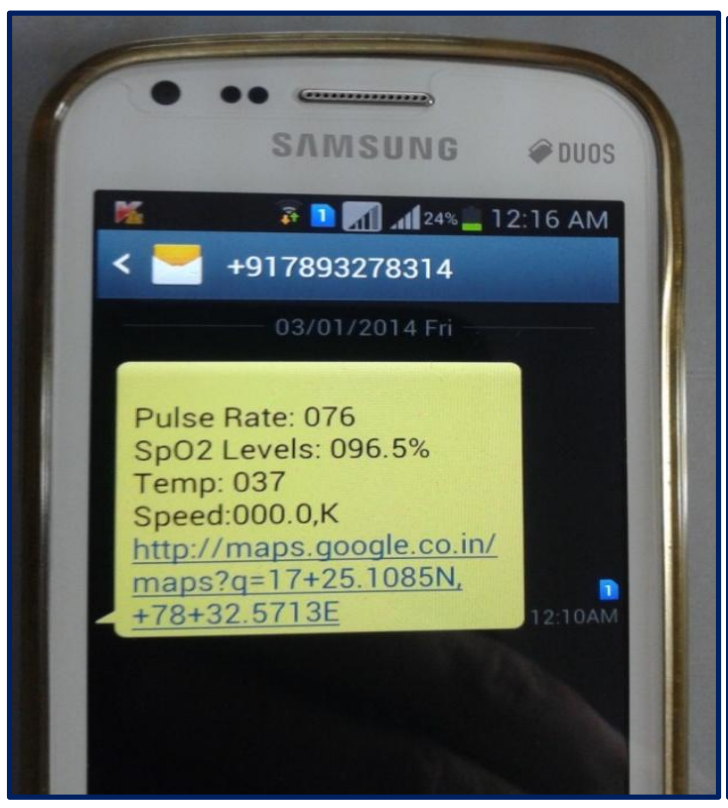

Fig. 7 Sample message received on mobile

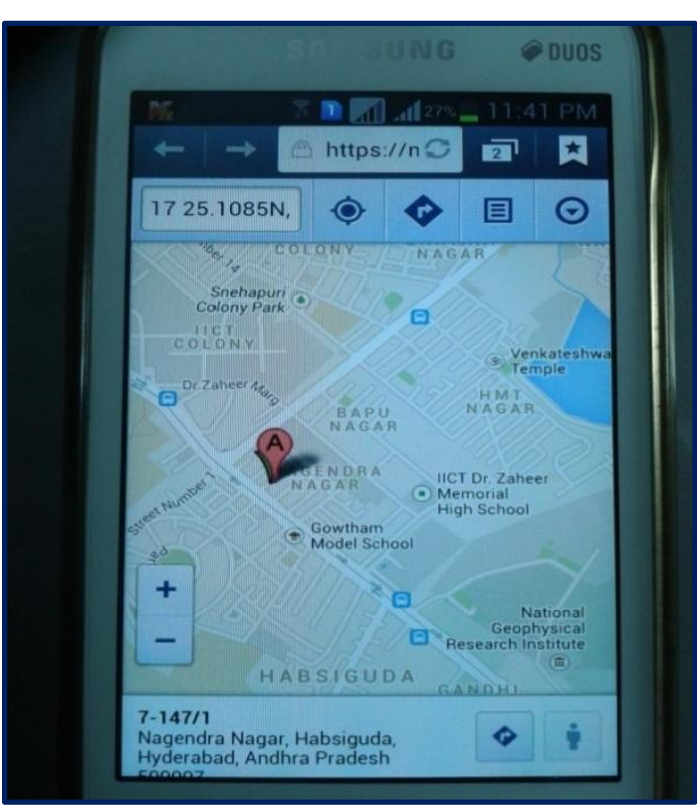

Fig. 8 Google map location of emergency vehicle 


\section{CONCLUSION}

In this paper, we have designed and developed a physiological parameter monitoring system for measurement of pulse rate, $\mathrm{SpO}_{2}$ and body temperature. The vehicle parameters including location, speed and fuel level are estimated. The LPC 2148 microcontroller based emergency patient monitoring system has been successfully tested for continuous monitoring of patient's health information and vehicle parameters. This type of system helps in saving time for treatment of the patient in emergency conditions and also for monitoring the vehicle parameters for proper management of vehicles in the emergency service network.

\section{REFERENCES}

[1] Bagha, S. and Shaw, L. (2011), "A Real Time Analysis of PPG Signal for Measurement of $\mathrm{SpO}_{2}$ and Pulse rate", International Journal of Computer Applications, Vol. 36, No. 11.

[2] John Allen (2007), "Photoplethysmography and its application in clinical physiological measurement", Physiological Measurement, Vol. 28, No. 3.

[3] LPC 214x User Manual (2012), Rev.4, 23 April, NXP Semiconductors, (http://www.nxp.com).

[4] http://www.emri.in/index.html.

[5] http://www.sunrom.com.

[6] http://www.ti.com/lit/ds/symlink/lm35.pdf. 